\title{
Serum neudesin levels in patients with polycystic ovary syndrome
}

\author{
Hamiyet Yılmaz $\operatorname{Yasar}^{1} \mathbb{D}$, Mustafa Demirpence ${ }^{1} \mathbb{D}$, Ayfer Colak $^{2} \mathbb{D}$, Merve Zeytinli² ${ }^{\mathbb{D}}$, \\ Erdem Yasar $^{3}{ }^{(10}$, Ali Taylan ${ }^{4}$ \\ ${ }^{1}$ Department of Endocrinology, Tepecik Research and Training Hospital, Izmir, Turkey \\ ${ }^{2}$ Department of Biochemistry, Tepecik Research and Training Hospital, Izmir, Turkey \\ ${ }^{3}$ Department of Anesthesiology and Algology, Katip Celebi University, Ataturk Research and Training Hospital, Izmir, Turkey \\ ${ }^{4}$ Department of Rheumatology, Tepecik Research and Training Hospital, Izmir, Turkey
}

\begin{abstract}
Objectives: We aimed to investigate serum neudesin levels that has neural, metabolic functions in patients with polycystic ovary syndrome (PCOS).

Material and methods: The study included 180 women (age range, 18-44 years) with a diagnosis of PCOS and a control group that included 100 healthy females (age range, 18-46 years). Body mass index (BMI), waist circumference, Ferriman-Gallwey score, was evaluated and plasma glucose, lipid profile, estradiol, progesterone, total testosterone, prolactin, insulin, dehydroepiandrosterone sulfate (DHEA-S), FSH, LH, free T3, free T4, thyroid stymulating hormone (TSH), anti-thyroperoxidase (anti-TPO) antibody and neudesin levels were evaluated in all participants.

Results: BMI and waist circumference were similar between two groups. Ferriman-Gallwey score was significantly higher in the patient group. Fasting blood glucose, HbA1C, lipid parameters except triglyceride levels, free T3, free T4, TSH, anti-TPO were similar between the two groups. Triglyceride, insulin and HOMA values were significantly higher in PCOS patients. While follicle-stimulating hormone (FSH), estradiol, progesterone, prolactin and DHEAS levels were similar, LH was significantly higher in patients with PCOS. Serum neudesin level was significantly lower in PCOS patients with respect to controls $(p=0.015)$. Neudesin was positively correlated with insulin $(r=0.224, p=0.037)$, and progesterone $(r=0.716$, $p=0.001$ ). Multiple regression analysis revealed that neudesin correlated with only progesterone (beta $=0.308, p=0.001$ ). Conclusions: Due to the association of decreased levels of neudesin with PCOS and correlation of neudesin with progesterone, neudesin may be related with one of patophysiologic pathways of PCOS. Still, it is not certain that decreased neudesin is involved in the pathogenesis of PCOS or is the result of the disorder.
\end{abstract}

Key words: neudesin; membrabe-associated progesteron receptors; pathogenesis of polycystic ovary syndrome

Ginekologia Polska 2022; 93, 7: 525-530

\section{INTRODUCTION}

Polycystic ovary syndrome (PCOS) is the most frequent reason of chronic anovulation with hyperandrogenemia affecting $5-10 \%$ of women of reproductive age $[1,2]$. This syndrome is characterized by hyperandrogenism (clinical and/or biochemical), oligo-amenorrhea and polycystic ovaries detected by pelvic ultrasound. Two out of these three criteria are sufficient for diagnosis according to the most widely used Rotterdam criteria (2003) [1]. The Androgen Excess Society (2006) defined PCOS by the presence of hyperandrogenism (clinical and/or biochemical), ovarian dysfunction (oligo-anovulation and/or polycystic ovaries) and the exclusion of related disorders such as Cushing's syndrome, congenital adrenal hyperplasia and/or androgen-secreting tumors $[1,3]$. PCOS not only leads to menstrual irregularities, infertility and miscarriage, but also increases the risk of endometrial cancer due to the long-term undefied estrogen effect [3]. PCOS is also associated with metabolic abnormalities and cardiovascular risk factors such as type 2 diabetes, dyslipidemia and obesity related to insulin resistance $[1,4-6]$.

The definite etiology of PCOS has not been determined; it is considered a heterogenous disorder with multifactorial causes and the genetic contributions remain incompletely

Corresponding author:

Hamiyet Yilmaz Yasar

Tepecik Research and Training Hospital, Department of Endocrinology, Guney district, Street number: 1140/1 no:1, 35110, Izmir, Turkey

phone: +90 23246969 69, e-mail: drhamiyetyilmaz@yahoo.com

Received: 13.01.2021 Accepted: 6.04.2021 Early publication date: 24.06 .2021

This article is available in open access under Creative Common Attribution-Non-Commercial-No Derivatives 4.0 International (CC BY-NC-ND 4.0) license, allowing to download articles and share them with others as long as they credit the authors and the publisher, but without permission to change them in any way or use them commercially. 
described. It has been suggested that the underlying causes of PCOS include the increased pulse frequency of gonadotrophin-releasing hormone $(\mathrm{GnRH})$, leading to increased amplitude and frequency of luteinizing hormone (LH) secretion and stimulation of theca cells to produce androgens; decresed levels of follicle-stimulating hormone (FSH) relative to $\mathrm{LH}$, insulin resistance in adipose tissue and skeletal muscles via a post-receptor defect (abnormal phosphorylation of thyrosine kinase), pancreatic beta-cell dysfunciton and obesity $[3,7,8]$.

Neudesin, one of the membrane-associated progesterone receptors, is a secreted protein with cytochrome 5-like heme/steroid-binding domain, has neural functions, participates in energy metabolism and tumorigenesis [9]. The distribution pattern of neudesin gene expression is very similar to the progesterone receptor in the rat forebrain, especially regions including anteroventral, periventricular, arcuate and ventromedial nuclei [10]. Therefore, it has been suggested that neudesin might be involved in regulation of neuroendocrine functions via progesterone receptors [10].

\section{Objectives}

As neuroendocrine abnormalities contribute to the pathogenesis of PCOS, we aimed to investigate serum neudesin levels (with neural and metabolic functions) in patients with PCOS. To date, there has only been one study about neudesin levels in patients with PCOS [11]. Therefore due to the scarcity of data, we aimed to investigate serum neudesin levels in patients with PCOS.

\section{MATERIAL AND METHODS}

\section{Patients study design}

This cross-sectional, case-control study included 180 women (aged 18-44 years) with a diagnosis of PCOS defined in accordance with the Rotterdam criteria [8]. The control group consisted of 100 healthy females (aged 18-46 years). The study was carried out between January 2017 and October 2018 at the Department of Endocrinology at Tepecik Research and Training Hospital. Women with chronic diseases such as overt hypothyroidism or hyperthyroidism, kidney or liver failure, hyperprolactinemia, late-onset adrenal hyperplasia, diabetes, hypertension or Cushing's syndrome as well as women taking thyroid hormones or anti-thyroid medication were excluded from the study. Additionally, women who had been receiving hormonal therapy, including oral contraceptive pills or steroids (glucocorticoids) within six months were excluded. The study was approved by the medical ethics committee of the Tepecik Research and Training Hospital and written informed consent was obtained from all the study subjects.

Body mass index (BMI) and waist circumference were measured in all study subjects. Hirsutism was evaluated based on the Ferriman-Gallwey scoring index over nine body areas [12].

Fasting venous blood was obtained from all study subjects to evaluate biochemical parameters including plasma glucose and lipid profile (total cholesterol, HDL cholesterol, LDL [low density lipoprotein] cholesterol and triglycerides) as well as hormones including estradiol, progesterone, total testosterone, prolactin, insulin, DHEA-S, FSH, LH, free T3, free T4, TSH and anti-thyroperoxidase (anti-TPO) antibodies. Serum samples were aliquoted, frozen and stored at $-80^{\circ} \mathrm{C}$ for neudesin analysis. The blood samples were obtained during the third to ninth days of the menstrual cycle or 60 days after the last menstrual period.

Pelvic ultrasonography was perfomed for all participants.

\section{Laboratory assessments}

Glucose, triglycerides, total cholesterol and high density lipoprotein (HDL) cholesterol levels were measured by enzymatic methods using an AU5800 autoanalyzer (Beckman Coulter Inc., CA, USA). LDL cholesterol was calculated by the Friedewald 's equation method. Insulin, FSH, $\mathrm{LH}$, total testosterone, estradiol, progesterone, prolactin, DHEAS levels, were analysed by chemiluminescence assay method using a Dxl immunoanalyser (Beckman Coulter Inc., CA, USA). Free T3, free T4, TSH, anti-TPO, levels were measured by chemiluminescent method by Immulite 2000 otoanalyzer (Immulite XPi, Siemens, Germany). Glycated hemoglobin ( $\mathrm{HbA} 1 \mathrm{c}$ ) was measured using boronate affinity high-performance liquid chromatography method (Trinity Biotech, Kansas City, MO, USA). Serum neudesin levels were measured using sandwich-enzyme-linked immunosorbent assay (ELISA) kit according to the manufacturer's instructions (Cat. No: E-EL-H3302, Elabscience Biotechnology Co.,Ltd, China). The intra-assay and inter-assay coefficients of variations were $7.4 \%$ and $6 \%$ for neudesin $(\mathrm{ng} / \mathrm{mL})$ respectively.

Homeostasis model assessment (HOMA) was calculated to measure insulin sensitivity by using the equation = fasting insulin $(\mathrm{mU} / \mathrm{L}) \times$ glucose $(\mathrm{mmol} / \mathrm{L}) / 22.5$. Insulin resistance is determined by having a HOMA value $>2.7$ [13]

\section{Pelvic ultrasonography}

Transabdominal pelvic ultrasonography was performed by using a Logiq 5 Pro unit (GE Medical Systems, WI, USA) and C1-5-RS (2-5 MHz) transducer. The ovaries were imaged in the sagittal and transverse planes. The presence of polycystic ovaries were defined as existence of 12 or more follicles throughout the ovary measuring 2-9 $\mathrm{mm}$ in diameter [1]. All ultrasonographic evaluations were performed by the same radiologist. 


\section{Statistical analysis}

Results are expressed as means \pm SD. The Chi-Square test was used for the comparison of non-parametric variables in both groups. The patient and control groups were compared by using Student-t test and Mann-Whitney U test. Correlation between serum neudesin levels and other parameters were assessed by Pearson's correlation analysis. Multiple regression analysis was used to assess the contribution of correlated parameters to neudesin. $P<0.05$ was considered statistically significant. Statistical analysis was performed with SPSS 20 statistical software.

\section{RESULTS}

Clinical characteristics of the patient and control groups are described in Table 1. The groups were similar according to age, BMI and waist circumference. Ferriman-Gallwey score was significantly higher in patient group $-8.95 \pm 2.94$ - compared to control group $7.10 \pm 4.11(p=0.002)$.

Fasting blood glucose and $\mathrm{HbA} 1 \mathrm{C}$ values, lipid parameters except triglyceride levels, free T3, free T4, TSH, anti-TPO were similar between the two groups (Tab. 2). Triglyceride levels were significantly higher in patients with PCOS com-

\begin{tabular}{|c|c|c|c|}
\hline & $\begin{array}{c}\text { Group } 1 \\
\text { (Patients with PCOS) } \\
(\mathrm{n}=180)\end{array}$ & $\begin{array}{c}\text { Group } 2 \\
\text { (Control Group) } \\
(n=100)\end{array}$ & p value \\
\hline Age [years] & $25.94 \pm 6.18$ & $28.12 \pm 7.27$ & 0.088 \\
\hline $\mathrm{BMI}\left[\mathrm{kg} / \mathrm{m}^{2}\right]$ & $29.77 \pm 6.65$ & $28.04 \pm 6.16$ & 0.173 \\
\hline Waist circumference $[\mathrm{cm}]$ & $89.72 \pm 15.36$ & $84.33 \pm 12.21$ & 0.072 \\
\hline Ferriman-Gallway index & $8.95 \pm 2,94$ & $7.10 \pm 4.11$ & $0.002^{*}$ \\
\hline
\end{tabular}

*Statistically significant, $\mathrm{p}$ value $<0.05 ; \mathrm{BMI}$ - body mass index; PCOS — polycystic ovary syndrome

Table 2. Laboratory parameters of the study population

\begin{tabular}{|c|c|c|c|}
\hline & $\begin{array}{c}\text { Group } 1 \\
\text { (Patients with PCOS) } \\
(\mathrm{n}=\mathbf{1 8 0})\end{array}$ & $\begin{array}{c}\text { Group 2 } \\
\text { (Control Group) } \\
(n=100)\end{array}$ & p value \\
\hline Fasting glucose [mg/dL] & $89.14 \pm 8.71$ & $86.92 \pm 7.12$ & 0.170 \\
\hline Insulin $[\mu \mathrm{U} / \mathrm{mL}]$ & $17.31 \pm 9.72$ & $10.23 \pm 7.76$ & $0.004^{*}$ \\
\hline HOMA & $3.85 \pm 2.22$ & $2.01 \pm 1.18$ & $0.004^{*}$ \\
\hline $\mathrm{HbA} 1 \mathrm{C}[\%]$ & $5.29 \pm 0.38$ & $5.21 \pm 0.24$ & 0.231 \\
\hline $\begin{array}{l}\text { LDL-cholesterol } \\
{[\mathrm{mg} / \mathrm{dL}]}\end{array}$ & $117.31 \pm 37.02$ & $116.35 \pm 29.22$ & 0.889 \\
\hline $\begin{array}{l}\text { HDL-cholesterol } \\
{[\mathrm{mg} / \mathrm{dL}]}\end{array}$ & $49.36 \pm 12.42$ & $50.35 \pm 9.41$ & 0.655 \\
\hline $\begin{array}{l}\text { Total cholesterol } \\
{[\mathrm{mg} / \mathrm{dL}]}\end{array}$ & $191.78 \pm 44.12$ & $186.21 \pm 35.25$ & 0.497 \\
\hline Triglyceride [mg/dL] & $126.72 \pm 72.59$ & $97.35 \pm 42.18$ & $0.023^{*}$ \\
\hline $\mathrm{FSH}[\mathrm{mlU} / \mathrm{mL}]$ & $5.67 \pm 2.15$ & $5.76 \pm 2.14$ & 0.834 \\
\hline $\mathrm{LH}[\mathrm{mlU} / \mathrm{mL}]$ & $5.97 \pm 2.11$ & $2.53 \pm 2.91$ & $0.024^{*}$ \\
\hline Estradiol [pg/mL] & $71.24 \pm 68.07$ & $69.38 \pm 53.21$ & 0.884 \\
\hline Total testosterone $[\mathrm{ng} / \mathrm{dL}]$ & $68.50 \pm 24.79$ & $46.71 \pm 13.31$ & $0.001^{*}$ \\
\hline Progesterone $[\mathrm{ng} / \mathrm{mL}]$ & $1.81 \pm 1.32$ & $1.96 \pm 0.48$ & 0.225 \\
\hline Prolactin [ng/mL] & $11.44 \pm 5.02$ & $12.10 \pm 6.25$ & 0.548 \\
\hline DHEA-S $[\mu \mathrm{g} / \mathrm{dL}]$ & $287.48 \pm 127.82$ & $252.56 \pm 111.08$ & 0.150 \\
\hline $\mathrm{fT} 3[\mathrm{pg} / \mathrm{mL}]$ & $3.64 \pm 0.38$ & $3.51 \pm 0.31$ & 0.100 \\
\hline fT4 [ng/mL] & $0.84 \pm 0.15$ & $0.85 \pm 0.11$ & 0.816 \\
\hline $\mathrm{TSH}[\mathrm{ulU} / \mathrm{mL}]$ & $2.12 \pm 1.07$ & $2.15 \pm 0.64$ & 0.882 \\
\hline Anti-TPO [IU/mL] & $58.92 \pm 35.87$ & $36.29 \pm 28.54$ & 0.453 \\
\hline Neudesin [ng/mL] & $1.19 \pm 1.08$ & $2.12 \pm 1.04$ & $0.015^{*}$ \\
\hline
\end{tabular}


pared to individuals in control group $(p=0.023)$. Likewise, fasting insulin levels and HOMA values were significantly higher in PCOS patients. Insulin level was $17.31 \pm 9.72 \mu \mathrm{U} / \mathrm{mL}$ in patient group, and $10.23 \pm 7.76 \mu \mathrm{U} / \mathrm{mL}$ in control group $(p=0.004)$. HOMA values in PCOS and control groups were $3.85 \pm 2.22$ and $2.01 \pm 1.18$, respectively $(p=0.004)$. While FSH, estradiol, progesterone, prolactin and DHEAS levels were similar, $\mathrm{LH}$ and total testosterone were significantly higher in patients with PCOS. LH level was $5.97 \pm 2.11 \mathrm{mlU} / \mathrm{mL}$ in patient group and $2.53 \pm 2.91 \mathrm{mIU} / \mathrm{mL}$ in control group $(p=0.024)$. Total testosterone level was $68.50 \pm 24.79 \mathrm{ng} / \mathrm{dL}$ in patient group, and $46.71 \pm 13.31 \mathrm{ng} / \mathrm{dL}$ in control group $(p=0.001)$. Progesterone levels were $1.81 \pm 1.32 \mathrm{ng} / \mathrm{mL}$ and $1.96 \pm 0.48 \mathrm{ng} / \mathrm{mL}$ in patient and control group, separately $(p=0.225)$. Serum neudesin level was significantly lower in PCOS patients $(1.19 \pm 1.08 \mathrm{ng} / \mathrm{mL})$ with respect to controls $(2.12 \pm 1.04 \mathrm{ng} / \mathrm{mL})(p=0.015)$.

The percentage of individuals with polycystic ovarian apperance on pelvic ultrasonography was higher in patients with PCOS compared to control group (70\% vs $18 \%, p=0.001$ ).

Correlation analysis were performed between neudesin and all the other parameters. Neudesin was positively correlated with insulin $(r=0.224, p=0.037), \operatorname{HOMA}(r=0.234$, $p=0.029)$ and progesterone $(r=0.716, p=0.001)$ (Fig. 1). No correlation was observed between neudesin level and other parameters. Multiple regression analysis showed that progesteron levels significantly contributed to neudesin levels (beta $=0.308, p=0.001$ ), however the contribution of insulin to neudesin was not statistically significant (beta $=-0.155$, $\mathrm{p}=0.140)($ Tab. 3)

\section{DISCUSSION}

PCOS is the most common endocrine disorder in reproductive-aged women and is associated with signs and symptoms of hyperandrogenemia as well as increased metabolic and cardiovascular risk factors. However, the exact etiology remains unrevealed. Increased $\mathrm{GnRH}$ pulse frequency and LH pulsatility and relatively decreased FSH levels contribute to the pathogenesis [3, 14]. Increased LH pulsatility leads to increased androgen production from theca cells, and relatively decreased FSH levels cause im- paired aromatization to estrogens, follicle maturation and ovulation. The increased $\mathrm{GnRH}$ pulse frequency is attributed to loss of negative feedback inhibition by progesterone which may be due to decreased progesterone levels or decreased effects because of hyperandrogenemia [14, 15]. In addition, PCOS-related insulin resistance due to abnormal phosphorylation of the insulin receptor by intracellular serine kinases in adipose tissue and skeletal muscle contributes to increased 17,20 -lyase activity of P450c17 in steroidogenic tissue and up-regulation of testosterone formation via increased HSD17B5 gene expression in adipose tissue $[16,17]$. Hyperinsulinemia augments LH stimulation of ovarian androgen production by up-regulating $\mathrm{LH}$-binding sites and enhancing androgen production at the level of cytochrome P450c17 [16, 18].

Membrane associated progesterone receptors are a group of four proteins with a similar heme-binding domain related to cytochrome b5 (a membrane-bound hemoprotein that functions as an electron carrier for microsomal cytochrome P450 monooxygenase systems) [19]. These four proteins progesterone receptor membrane component 1 (PGRMC1), PGRMC2, neudesin and neuferricine, have diverse functions associated with cholesterol/steroid biosynthesis, drug metabolism and response. They interact with Cytochromes P450 (CYPs) and modulate their functions [19, 20]. Only PGRMC1 has been reported to bind progesterone $[10,21,22]$ and it is suggested that PGRMC1 might mediate

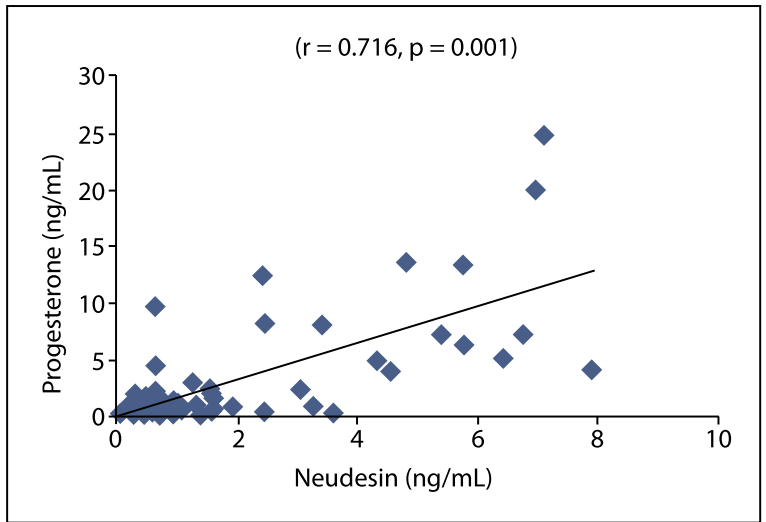

Figure 1. Correlation between neudesin and progesterone Table 3. Evaluation of the effect of insulin, HOMA and progesterone on neudesin using the multiple regression analysis $\left(\mathbb{R}^{2}=0.577\right)$

\begin{tabular}{|c|c|c|c|}
\hline Variables & $\beta$ & $\begin{array}{c}95 \% \mathrm{Cl} \\
\text { Min Max }\end{array}$ & $p$ value \\
\hline Insulin & -0.155 & -0.3630 .052 & 0.140 \\
\hline HOMA & 0.843 & -0.0691 .755 & 0.07 \\
\hline Progesterone & 0.308 & 0.2440 .373 & $0.001^{*}$ \\
\hline
\end{tabular}

Multiple regression analysis was used. $\beta$ : Unstandardized regression coefficient; ${ }^{*} p$ value of $<0.05$ was considered as significant; $\mathrm{Cl}-$ confidence interval; HOMA — homeostasis model assessment 
the rapid effects of progesterone [10]. PGRMC1 was found in immortalized GnRH neurons (GT1-7cells) [23] and rapidly inhibited the fluctuations of intracellular calcium levels in $\mathrm{GnRH}$ neurons [10, 24], leading to inhibition of GnRH and $\mathrm{LH}$ release. Neudesin is expressed in numerous tissues such as, brain, adipose tissue, heart and lungs, preferentially in neurons. It promotes differentiation of neurons through protein kinase and phosphotidylinositol-3 kinase pathways by using its' (cytochrome b5-like) heme/steroid-binding domain $[10,25]$. It is also strongly expressed in hypothalamic nuclei that regulate food intake and recombinant neudesin administration into the cerebral ventricle, resulting in decreased appetite and body weight with increased expression of pro-opiomelanocortin and melanocortin 4 receptors in the hypothalamus [12, 25-27]. In contrast to this finding, in another study, increased sympathetic activity was found in neudesin $\mathrm{KO}$ mice fed with high fat diet leading to increased energy consumption, fatty acid oxidation in brown adipose tissue and enhanced lipolysis in white adipose tissue [12, $28,29]$. It was suggested that the discrepancy between the two sets of data might be caused because the physiologic effect of neudesin was analyzed in neudesin $\mathrm{KO}$ mice and the pharmacological effect of neudesin was analyzed by the administration of recombinant neudesin [9]. Neudesin expression was also identified in various cancers and it was involved in tumorigenesis. Although the mRNA distribution pattern of neudesin and progesterone receptors is similar, and there is a structural similarity between PGRMC1 (which binds to progesterone) and neudesin, there is no data about the interaction between neudesin and progesterone [24, 28]. It is proposed that neudesin may act as a binding protein for lipophilic progesterone and hold it on the cell sufrace in the extracellular enviroment and this complex may act on the unknown cell surface progesterone receptor to exert a rapid effect [28].

The data are limited on the evaluation of membrane-associated progesterone receptors in patients with PCOS. PGRMC1 expression was reported in ovary tissues of PCOS rat models [29] and PGRMC1 expression in peripheral leukocytes was decreased in a study of patients with PCOS [30]. In the latter study, serum PGRMC1 levels were evaluated twice weekly, in addition to estradiol and progesterone levels, over four-week period. PGRMC1 levels were stable during the study period, and there was no correlation between PGRMC1 and estradiol and progesterone levels. Markedly reduced levels of PGRMC1 protein in PCOS patients were reported compared to healthy cycling women in the early follicular phase and it was suggested that PGRMC1 levels were strongly associated with ovulatory function [30]. However, to date, there is only one recently published study about neudesin as related to PCOS. In that study, researchers found decreased levels of neudesin in patients with PCOS and a negative correlation between neudesin and proges- terone. Likewise, in our study, we observed significantly decreased neudesin levels despite of similar progesterone levels between the two groups and a positive correlation between progesterone and neudesin levels. Although this cross-sectional study that does not imply causality, it might lead to a discovery of a relation between neudesin and PCOS. It may support the hypothesis that progesterone cannot exert a negative feedback effect on $\mathrm{GnRH}$ in combination with a relative deficiency of neudesin, and this may contribute to the pathogenesis of PCOS. Still, it is not certain that decreased neudesin is involved in the pathogenesis of PCOS or is the result of the disorder.

\section{CONCLUSIONS}

Due to the association of decreased levels of neudesin with PCOS and the correlation of neudesin with progesterone, neudesin may be hypothesized as an inter-relater in one of the pathophysiologic pathways of PCOS. Still, it is not certain that decreased neudesin is involved in the pathogenesis of PCOS or is the result of the disorder. However, further studies should be carried out to elucidate the neuroendocrine functions of neudesin and novel mechanisms regulating the progesterone effect in patients with PCOS.

\section{Author contributions}

All the authors contribute to conception of the work, acquisition, analysis and interpretation of data, drafting the work or revising it for intellectual content, final approval of the version to be published and agree to be accountable for all aspects of the work in ensuring that questions related to the accuracy or integrity of any part of the work are appropriately investigated and resolved.

\section{Statement of ethics}

All procedures performed in this study were in accordance with the ethical standarts of the medical ethics commitee of the Tepecik Research and Training Hospital with a decision file number: 2018/3-19 and with the declaration of Helsinki. All the participants of the study have given their informed consent.

\section{Conflict of interest}

The authors have no conflicts of interest to declare.

\section{Funding}

No funding for this study.

\section{REFERENCES}

1. Azziz R, Carmina E, Dewailly D, et al. Androgen Excess Society. Positions statement: criteria for defining polycystic ovary syndrome as a predominantly hyperandrogenic syndrome: an Androgen Excess Society guideline. J Clin Endocrinol Metab. 2006; 91(11): 4237-4245, doi: 10.1210/jc.2006-0178, indexed in Pubmed: 16940456. 
2. Adams J, Polson DW, Franks S. Prevalence of polycystic ovaries in women with anovulation and idiopathic hirsutism. Br Med J (Clin Res Ed). 1986; 293(6543): 355-359, doi: 10.1136/bmj.293.6543.355, indexed in Pubmed: 3089520.

3. Bednarska S, Siejka A. The pathogenesis and treatment of polycystic ovary syndrome: what's new? Adv Clin Exp Med. 2017; 26(2): 359-367, doi: 10.17219/acem/59380, indexed in Pubmed: 28791858.

4. Dunaif A. Insulin resistance and the polycystic ovary syndrome: mechanism and implications for pathogenesis. Endocr Rev. 1997; 18(6): 774-800, doi: 10.1210/edrv.18.6.0318, indexed in Pubmed: 9408743.

5. Çakır E, Çakal E, Özbek M, et al. The correlation between polycystic ovary syndrome and cardiovascular disease risk. Turk Jem. 2013; 17: 33-37.

6. Bozkırlı E, Bakıner O, Ertörer $E$, et al. Insulin resistance in non-obese polycystic ovary syndrome subjects and relation with family history of diabetes mellitus. Turk Jem. 2015; 19(2): 55-59, doi: 10.4274/tjem.2761.

7. Wołczyński S, Zgliczyński W. Abnormalities of the menstrual cycle. In: Zgliczyński W. ed. Large interna - Endocrynology. Medical Tribune Poland, Warszawa 2012: 561-567.

8. The Rotterdam ESHRE/ASRM-sponsored PCOS Consensus Workshop Group. Revised 2003 consensus on diagnostic criteria and long-term health risks related to polycystic ovary syndrome. Fertil Steril. 2004; 81(1): 19-25, doi: 10.1016/j.fertnstert.2003.10.004, indexed in Pubmed: 14711538.

9. Ohta $\mathrm{H}$, Kimura I, Konishi $\mathrm{M}$, et al. Neudesin as a unique secreted protein with multi-functional roles in neural functions, energy metabolism, and tumorigenesis. Front Mol Biosci. 2015; 2: 24, doi: 10.3389/fmolb.2015.00024, indexed in Pubmed: 26042224.

10. Petersen SL, Intlekofer KA, Moura-Conlon PJ, et al. Novel progesterone receptors: neural localization and possible functions. Front Neurosci. 2013; 7: 164, doi: 10.3389/fnins.2013.00164, indexed in Pubmed: 24065878.

11. Bozkaya G, Fenercioglu O, Demir İ, et al. Neudesin: a neuropeptide hormone decreased in subjects with polycystic ovary syndrome. Gynecol Endocrinol. 2020; 36(10): 849-853, doi: 10.1080/09513590.2020.1751106, indexed in Pubmed: 32314607.

12. Ferriman $D$, Gallwey JD. Clinical assessment of body hair growth in women. J Clin Endocrinol Metab. 1961; 21: 1440-1447, doi: 10.1210/jcem-2111-1440, indexed in Pubmed: 13892577.

13. Matthews DR, Hosker JP, Rudenski AS, et al. Homeostasis model assessment: insulin resistance and beta-cell function from fasting plasma glucose and insulin concentrations in man. Diabetologia. 1985; 28(7): 412-419, doi: 10.1007/BF00280883, indexed in Pubmed: 3899825.

14. Burt Solorzano CM, Beller JP, Abshire MY, et al. Neuroendocrine dysfunction in polycystic ovary syndrome. Steroids. 2012; 77(4): 332-337, doi: 10.1016/j.steroids.2011.12.007, indexed in Pubmed: 22172593.

15. Waldstreicher J, Santoro NF, Hall JE, et al. Hyperfunction of the hypothalamic-pituitary axis in women with polycystic ovarian disease: indirect evidence for partial gonadotroph desensitization. J Clin Endocrinol Metab. 1988; 66(1): 165-172, doi: 10.1210/jcem-66-1-165, indexed in Pubmed: 2961784.

16. Rosenfield RL, Ehrmann DA. The Pathogenesis of Polycystic Ovary Syndrome (PCOS): the hypothesis of PCOS as functional ovarian hyperandrogenism revisited. Endocr Rev. 2016; 37(5): 467-520, doi: 10.1210/er.20151104, indexed in Pubmed: 27459230.

17. Wu S, Divall S, Nwaopara A, et al. Obesity-induced infertility and hyperandrogenism are corrected by deletion of the insulin receptor in the ovarian theca cell. Diabetes. 2014;63(4): 1270-1282, doi: 10.2337/db131514, indexed in Pubmed: 24379345.

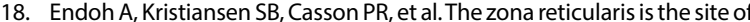
biosynthesis of dehydroepiandrosterone and dehydroepiandrosterone sulfate in the adult human adrenal cortex resulting from its low expression of 3 beta-hydroxysteroid dehydrogenase. J Clin Endocrinol Metab. 1996; 81(10): 3558-3565, doi: 10.1210/jcem.81.10.8855801, indexed in Pubmed: 8855801.

19. Ryu C, Klein K, Zanger U. Membrane associated progesterone receptors: promiscuous proteins with pleiotropic functions - focus on interactions with cytochromes P450. Frontiers Pharmacol. 2017; 8: 159, doi: 10.3389/fphar.2017.00159.

20. Hughes AL, Powell DW, Bard $M$, et al. Dap1/PGRMC1 binds and regulates cytochrome P450 enzymes. Cell Metab. 2007; 5(2): 143-149, doi: 10.1016/j.cmet.2006.12.009, indexed in Pubmed: 17276356

21. Peluso JJ, Romak J, Liu X. Progesterone receptor membrane component-1 (PGRMC1) is the mediator of progesterone's antiapoptotic action in spontaneously immortalized granulosa cells as revealed by PGRMC1 small interfering ribonucleic acid treatment and functional analysis of PGRMC1 mutations. Endocrinology. 2008; 149(2): 534-543, doi: 10.1210/en.2007-1050, indexed in Pubmed: 17991724.

22. Peluso JJ, Liu X, Gawkowska A, et al. Progesterone activates a progesterone receptor membrane component 1-dependent mechanism that promotes human granulosa/luteal cell survival but not progesterone secretion. J Clin Endocrinol Metab. 2009; 94(7): 2644-2649, doi: 10.1210/jc.2009-0147, indexed in Pubmed: 19417032.

23. Krebs CJ, Jarvis ED, Chan J, et al. A membrane-associated progesterone-binding protein, $25-\mathrm{Dx}$, is regulated by progesterone in brain regions involved in female reproductive behaviors. Proc Natl Acad Sci U S A. 2000; 97(23): 12816-12821, doi: 10.1073/pnas.97.23.12816, indexed in Pubmed: 11070092.

24. Bashour NM, Wray S. Progesterone directly and rapidly inhibits $\mathrm{GnRH}$ neuronal activity via progesterone receptor membrane component 1. Endocrinology. 2012; 153(9): 4457-4469, doi: 10.1210/en.2012-1122, indexed in Pubmed: 22822163.

25. Kimura I, Nakayama Y, Yamauchi H, et al. Neurotrophic activity of neudesin, a novel extracellular heme-binding protein, is dependent on the binding of heme to its cytochrome b5-like heme/steroid-binding domain. J Biol Chem. 2008; 283(7): 4323-4331, doi: 10.1074/jbc. M706679200, indexed in Pubmed: 18056703.

26. Byerly MS, Swanson RD, Semsarzadeh NN, et al. Identification of hypothalamic neuron-derived neurotrophic factor as a novel factor modulating appetite. Am J Physiol Regul Integr Comp Physiol. 2013; 304(12): R1085-R1095, doi: 10.1152/ajpregu.00368.2012, indexed in Pubmed: 23576617

27. Ohta $\mathrm{H}$, Konishi $\mathrm{M}$, Kobayashi $\mathrm{Y}$, et al. Deletion of the neurotrophic factor neudesin prevents diet-induced obesity by increased sympathetic activity. Sci Rep. 2015; 5: 10049, doi: 10.1038/srep10049, indexed in Pubmed: 25955136.

28. Kimura I, Nakayama Y, Zhao Y, et al. Neurotrophic effects of neudesin in the central nervous system. Front Neurosci. 2013; 7: 111, doi: 10.3389/fnins.2013.00111, indexed in Pubmed: 23805070.

29. Zheng $Q$, Li Y, Zhang $D$, et al. ANP promotes proliferation and inhibits apoptosis of ovarian granulosa cells by NPRA/PGRMC1/EGFR complex and improves ovary functions of PCOS rats. Cell Death Dis. 2017; 8(10): e3145, doi: 10.1038/cddis.2017.494, indexed in Pubmed: 29072679.

30. Schuster J, Karlsson T, Karlström PO, et al. Down-regulation of progesterone receptor membrane component 1 (PGRMC1) in peripheral nucleated blood cells associated with premature ovarian failure (POF) and polycystic ovary syndrome (PCOS). Reprod Biol Endocrinol. 2010; 8: 58, doi: 10.1186/1477-7827-8-58, indexed in Pubmed: 20537145. 